\title{
Experience with application of reagent to heat transfer surfaces of combustion device
}

\author{
Veronika Blahůšková, Jozef Vlček, Barbora Grycová*, Dalibor Jančar, Marek Velička \\ VSB - Technical University of Ostrava, Institute of Environmental Technology, 17. listopadu 15/2172, Ostrava-Poruba \\ 708 33, Czech Republic \\ "Corresponding author: e-mail: barbora.grycova@vsb.cz
}

\begin{abstract}
The formation of deposits on heat exchange surfaces of combustion equipment causes a decrease in heat exchange, a decrease in power, and consequently deterioration in the economic balance of combustion equipment. The technology of French company A. I. T. DRIVEX has been developing and being applied in practice for many decades. Preventive technology is used as a mean reagent periodically injected during operation into the combustion chamber. Part of the application is always pre-prepared project resolving the location of the injection nozzles into the combustion chamber on the flue gas path. The article describes the experimental usage of reagent GEPERSUITE 2200 at the Sermaize refinery in France. The aim of the test is to evaluate the benefits and advantages of applied technology in the boiler refinery in full operation. The results clearly demonstrate that using the reagent GEPERSUITE 2200 is advantageous in terms of economic and technical properties.
\end{abstract}

Keywords: refinery de Sermaize, combustion equipment, heat transfer surfaces, DRIVEX, cleaning deposits.

\section{INTRODUCTION}

Maintenance of the heat transfer surfaces of power equipment ${ }^{1}$, incineration of municipal and industrial waste $^{2}$, is currently being solved intensively both in this country and abroad.

Technical progress in the field of combustion ${ }^{3}$ and increasing demands are placed on efficiency, safety of operation and ease of operation combustion plants is reflected in the need of support operators in the optimization of combustion processes ${ }^{4}$. Experience confirms the problem fouling of heat transfer surfaces of boilers ${ }^{5}$ does not apply only to the operators of power equipment, but also to the purchasers of energy consumers. The studies of renovated institutions estimate ${ }^{6,7}$ that unwanted deposits on heat transfer surfaces on the flue gas area and media of all types thermal energy equipment cause major financial losses, not counting subsequent operating losses caused by equipment downtime, or due to repairs.

Combustion of heavy fuel oil, coal, wood, municipal and industrial waste in boilers is associated with the formation of solid residues ${ }^{8}$, containing a certain amount of mechanical unburned. These are mainly incineration plants using coal as fuel, heating oil, timber and heat exchangers positioned ${ }^{9}$ behind gas engines.

Deposits $^{10}$ on heat transfer surfaces consist mainly of imperfectly burned particles with higher carbon content ${ }^{11}$ due to the inappropriate composition of the burned fuel, the development of the crude oil refining process and the diversification of fuel supplies.

Similar problems occur in cogeneration units with internal combustion engines, wherein the leakage of a small amount of lubricating oil into the combustion chamber and its subsequent combustion is associated with the flue gas pollution and the formation of deposits on the heat exchange surfaces. The resulting deposits have an impact on heat transfer of flue gas leading to a deterioration equipment efficiency and higher fuel consumption $^{12}$. They also significantly contribute to the corrosion of the affected parts. The combustion products contain nitrogen, sulphur, chlorine, fluorine derivatives, etc., as a result of element transformation during the combustion process ${ }^{13},{ }^{14}$. These derivatives are very dangerous for the environment, as well as for ceramic and metal materials used in the construction of burning equipment.

The melting temperature of ash forming during the combustion of fossil fuels, incineration of industrial and municipal waste is very low. This temperature is lower than the surface temperature of materials (both metal and ceramic) inside the combustion chamber as well as in the linked technological units. Some ashes, especially vanadium-sodium ones, formed during the combustion of heavy fuel oils, are extremely aggressive with respect to corrosion, if the temperature of heat exchange surfaces reaches values of $450-500^{\circ} \mathrm{C}$.

Unburnt carbon residues ${ }^{15}$, which are able to bind $\mathrm{SO}_{3}$, also contribute to the increased risk of low-temperature corrosion ${ }^{16}$ and to forming very hard and strongly adhering deposits in "cold“ parts of the combustion equipment (superheaters, economisers, etc.). This is the basis for forming acidic combustion products in the equipment burning heating oils with high content of sulphur, which subsequently becomes the source of air pollution. Bonded $\mathrm{SO}_{3}$ under certain temperature conditions (metal surface temperature $150-160^{\circ} \mathrm{C}$ ) gives upon contact with moisture possibility formation of $\mathrm{H}_{2} \mathrm{SO}_{4}$, which attacks metallic materials and causes the formation of very hard sulfates and firmly adhering deposits.

During the combustion, unburnt particles and ash are carried away by combustion products. Pollutants in flue gases at the boiler outlet present in the form of solid particles ${ }^{17}$ in the gas phase. Melted and partially-melted ash is caught on heat exchange surfaces and causes a progressive growth in the deposited layer. The deposits then cause a lowering of heat exchange ${ }^{18}$ on heat exchange surfaces and there is also decrease in power and combustion equipment yield. This is accompanied by the increase in the temperature of combustion products at the combustion equipment output. If these losses exceed certain limits, it is necessary to change the mode of ope- 
ration of combustion equipment; besides, flues could be completely clogged. If the combustion equipment is not provided with devices for cleaning combustion products (cyclones, textile filters, electrostatic filters, washers, etc.) some solid particles, which are not caught on the walls of the combustion equipment, are subsequently released into the atmosphere.

\section{„MECHANICAL" AND "NON-MECHANICAL" TECH- NOLOGIES FOR MAINTAINING CLEANLINESS OF THE COMBUSTION EQUIPMENT}

To decrease the formation of deposits (resulting in the equipment being shut down, increases in fuel consumption, etc.), a lot of systems for cleaning have been designed and operated. To the best known methods include blow cleaning or jet washing of heat exchange surfaces. There are also vibration, chipping and acoustic mechanical systems for removing the deposits falling off to the grates or to the lower parts of the combustion area or individual flue drafts. In general, it can be concluded that these methods are efficient if the deposits are "dry", i.e. brittle and not so adherent. Failing that, the amount of the deposits increases until it is necessary to shut down the equipment due to cleaning.

Air and steam blowers ${ }^{\mathbf{1 9}}$ are generally devices with high power consumption and they also need intensive maintenance to be efficient enough ${ }^{\mathbf{1 1}}$. Moreover, if the blowing device is not absolutely clean (if it contains some water) it will result in low-temperature corrosion, which is hazardous for metal parts of the equipment. If the combustion equipment is not provided with a dedusting device, the operation of cleaning equipment is always connected with considerable increase in the content of dust in combustion products released into the atmosphere. Using these cleaning systems results in an increase of emissions also in the case of equipment provided with a dedusting device.

The idea to use a chemical agent which has an impact on deposit forming on heat exchange surfaces as a well as on the walls of the combustion equipment is not new. Using common salt to activate combustion and removing soot was already known to our ancestors. There is one significant disadvantage connected with this method - accelerated decay of metal components, on which chlorates form due to contact with salt. It is essential that the proposed chemical methods for cleaning the internal parts of combustion chambers and boilers meet technical as well as economic criteria.

\section{Characteristics of reagent}

Reagent ${ }^{20}$ can be characterized as no aggressive substances without affecting to the materials used in the construction of the combustion device. Dosage is determined according to the problem at hand and the goals to reach. They are consisted of a metal salt compound soluble in water suitably selected depending on their use.

The composition of the reagent is apparent from the pretreated study of the combustion device, which is used. The principle of the technology consists in the creation of recovering a thin layer (a film) all the heat exchange surfaces of the combustion device, if it is possible. Reagent compositions are the most often injected directly into the flame, or above the layer of burning fuel on the grate and the flue gas on the way.

Features reagent particle is alkaline, not harmful to the materials of construction of the combustion apparatus or the environment. Depending on the type, the reagent performs the following functions:

- allow the oxidation of unburned carbon particles,

- prevent or restrict the sticking of melted and fused ash particles, on all surfaces, including the combustion chamber, including the heat transfer surfaces,

- fulfills both functions simultaneously,

- if there is a deposit, not monolithic-hard, but due to the periodic injection of reagent has a sandwich character and therefore a better mechanical properties for cleaning (deposit is a fragile, easily removable).

As you can see on Figure 1, periodic injection allows to create a layer-film on the heat transfer surfaces, which is reacted gradually and prevent the formation of hard, very cohesive and adherent deposits. If the deposits occur, they are easily removable and generally limited by their production.

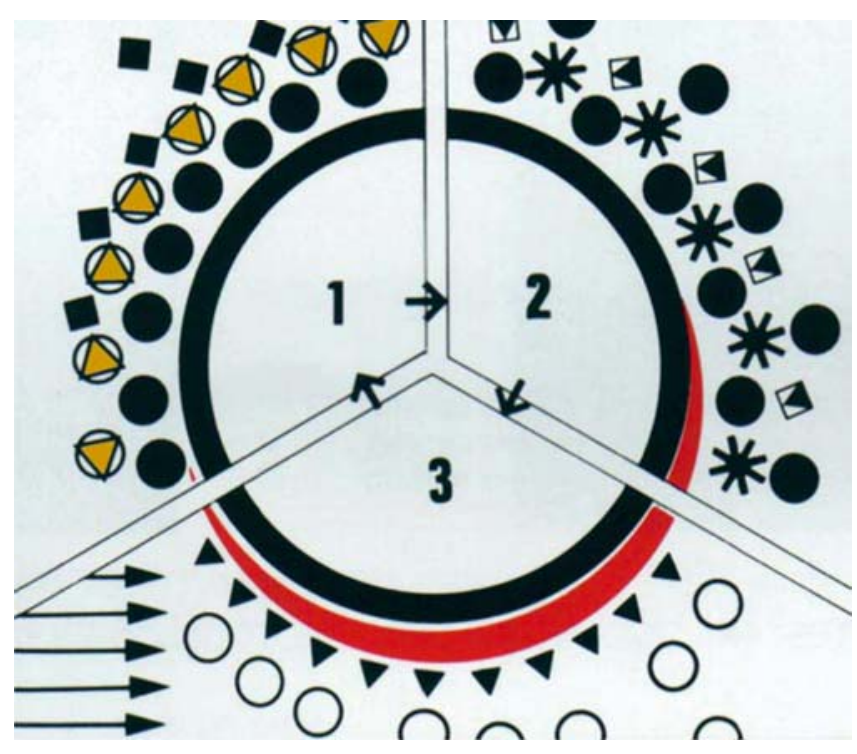

Figure 1. Cut of heat transfer surface during process of periodic reagent injection. 1 - deposits (not mechanically removed); 2 - effect of reagent, penetration of the reagent toward to the transfer surface; 3 - the emergence of reagent layer; deposits falling off forcibly (mechanical cleaning of devices) or unintentionally, the film remains neutralization $(\mathrm{pH} \sim 7)$

\section{Description}

The long-term existence of the reagent layer and its periodic renewal injection does not depend on the amount of injected reagent or the amount of fuel consumed, or changes load of the combustion device. This simplifies the injection system, which may be entirely or partially automated.

To achieve the highest efficiency of the process is the most important complete distribution of the reagent in the combustion chamber, consequently a suitable number of spray nozzles and their deployment.

\section{RESULTS AND DISCUSSION}

For the assessment of efficient and competitive used preventive technology DRIVEX ${ }^{\mathbf{2 1}}$ was selected by the 
consent of management the French RAFINERY de SERMAIZE les Bains (118, Av. Doct. David Rosenfled, 92230 Romainville).

GEPERSUITE 2200 was selected as the reagent for the experiment, the substance specific to their composition injected into the flame of the burning of the coal layer, or into the oil burners and also dispersed into all parts of the flues, where the flue gas temperature is higher than $200^{\circ} \mathrm{C}$.

GEPERSUITE 2200 is able to create and keep on all heat exchangers, with periodical re-injections, a film of high-fusion level reactive particles $\left(=2600^{\circ} \mathrm{C}\right)$. Exclusively made with hydro soluble magnesium salts, the DRIVEX 2200 reagent instantly decomposes in the flame and frees magnesium oxides particles $(\mathrm{MgO})$ which are carried by the combustion gases into the heat-exchangers where they settle down.

Physico-chemical specifications GEPERSUITE 2200: light pink pulverized product, with $\mathrm{pH}$ 6,9, whose main component is magnesium $\left(65,5 \mathrm{~g} \cdot \mathrm{l}^{-1}\right)$. Magnesium with admixture the alkali metals is present in the form of magnesium oxide $(\mathrm{MgO})$ and in the form of magnesium chloride $\left(\mathrm{MgCl}_{2}\right)$. The specific weight of the GEPERSUITE 2200 reagent is $1100 \mathrm{~kg} \cdot \mathrm{m}^{-3}$. The DRIVEX 2200 reagent is delivered in 240 kilos plastic kegs or 1100 kilos ISO containers.

Table 1. Basic data of RAFINERY de SERMAIZE

\begin{tabular}{|l|c|}
\hline Combustion equipment & 2 mechanical grates \\
\hline Steam output & $15 \mathrm{t} \cdot \mathrm{hr}^{-1}$ \\
\hline Steam pressure & $24 \mathrm{bars}$ \\
\hline Superheated steam temperature & $400^{\circ} \mathrm{C}$ \\
\hline Heating area & $650 \mathrm{~m}^{2}$ \\
\hline Surface area of overheating & $72 \mathrm{~m}^{2}$ \\
\hline
\end{tabular}

Table 1 gives us the basic information about the selected refinery.

The refinery is combusted continuously in a one-tensile vertical boiler with a movable mechanical grid. The black coal is used as a fuel in the combustion, granulometry of the coal is $0 / 6 \mathrm{~mm}$.

\section{Targets of using the reagent GEPERSUITE 2200}

The reagents should lead to avoid sticking of the molten ash contained in the flue gas on the heat transfer surfaces of the combustion equipment and also to disposal / destruction of unburned carbon particles, which are deposited on these surfaces. During the periodical injection of the reagent the reagent film is formed on the surfaces (with the shape of "sandwich") and the deposits are then more easily removed, in many cases just by sloughing.

The main objective of the use of liquid reagent GEPERSUITE 2200 in refinery de Sermaize should be:

- Keep the heat transfer surfaces clean as long as possible to reduce fuel consumption. Avoid during 6 weeks commissioning of the boiler no. 2 for cleaning purposes.

- Use less frequently existing steam cleaning equipment.

- Facilitate the heat transfer surfaces cleaning during periodic shutdowns of the boiler.

By using reagent GEPERSUITE 2200 should be achieved operating costs reduction related to the operation of the system. Application of this method should not cause a larger technical adjustments to the incinerator.

\section{Verification of using the reagent GEPERSUITE 2200}

Before using the reagent, it is necessary to get rid of the heat exchange surface from dust and other deposits. This can be achieved by an intensive blowing for several days. Heat transfer surfaces are formed by horizontally disposed tube bundles. Manual cleaning of these surfaces is very difficult and cannot be completely performed.

After locating the extent of deposits in the combustion space the balance sheet was made about the application of technology, including the annual schedule of the experiment according to planned shutdowns device. Removal of deposits is carried out periodically, either by blowing of heat transfer surfaces or by mechanical cleaning during the shutdown. Equipment shutdown represents the additional costs due to maintenance of

Table 2. Data of equipment cleaning

\begin{tabular}{|l|c|c|}
\hline Steam blower & $\begin{array}{c}1 \times \text { per } \\
24 \mathrm{~h}\end{array}$ & \\
\hline $\begin{array}{l}\text { Shutdown } 24 \mathrm{~h}- \\
\text { cleaning }\end{array}$ & $\begin{array}{c}1 \times \mathrm{p} \\
\text { per14 } \\
\text { days }\end{array}$ & $\begin{array}{c}\text { Replacement operation - } \\
\text { boiler no. 2, combustion of } \\
\text { heavy fuel oil }\end{array}$ \\
\hline $\begin{array}{l}\text { Shutdown } \\
1 \text { mounth - total } \\
\text { cleaning }\end{array}$ & $\begin{array}{c}1 \times \text { per } \\
\text { year }\end{array}$ & \\
\hline
\end{tabular}

equipment and loss of energy production. Current plan associated with cleaning of the combustion in refineries de Sermaize demonstrates Table 2.

After the agreement the installation of technology was attended by workers of DRIVEX company. The connection to the operating compressed air (6 bar), the programmable controller and accessories (dosing pump) and the connection to the power supply $400 \mathrm{~V} / 3 \mathrm{f}$ is required for operation of own equipment. The connection of Eurocontainer containing reagent GEPERSUITE 2200 is performed with pump hose. After completing the installation, the injection has been set on a programmable machine, according to empirical experience.

\section{Dosing of the reagent GEPERSUITE 2200}

\section{1. week}

Injection of reagent is divided into 6 doses per day (every 4 hours). Blowing of heat transfer surfaces is carried out in normal mode.

\section{2.-3. week}

Reagent dosing in the same way as in the first week, but without the blowing during the night shift.

\section{4. week}

Reagent dosing in the same way as in the first week, but without blowing during the afternoon and night shifts.

In the final stage dosing of reagent, which corresponds to the quantity of about $2-3 \mathrm{~kg}$ of reagent per 10 tons of fuel was adjusted. Daily dosing is automatic and total dosing time is about 2 minutes.

Note: The advantage of reagent GEPERSUITE 2200 is his good adhesion on surfaces. Therefore it is not necessary to change the dosage, according to the fluctuations in fuel consumption. 


\section{Evaluation of DRIVEX technology}

In terms of equipment reliability it must be noted that throughout the duration of the experiment, no failure of equipment DRIVEX was recorded. During the experiment control of the injector was also carried out. Throughout the experiment, the nozzle showed a normal wear even though it was disposed in a place at $700-800^{\circ} \mathrm{C}$.

There were chosen two comparative periods to evaluate the potential benefits of technology DRIVEX after 12 months.

Of the parameters in Table 3 it can be stated, the reduction of the number of steam blowing and increasing the heat transfer efficiency has also been reported. The shutdowns for manual cleaning were completely removed

Table 3. Parameters with/without reagent

\begin{tabular}{|l|c|c|}
\hline $\begin{array}{l}\text { Selected comparative } \\
\text { parameters }\end{array}$ & $\begin{array}{c}\text { Start of the } \\
\text { campaign }\end{array}$ & $\begin{array}{c}\text { End of the } \\
\text { campaign }\end{array}$ \\
\hline $\begin{array}{l}\text { Frequency of steam soot } \\
\text { blowers [day] }\end{array}$ & 3 & 1 \\
\hline $\begin{array}{l}\text { Steam consumption during } \\
\text { blowing [t] }\end{array}$ & 6 & 2 \\
\hline $\begin{array}{l}\text { Flue gas temperature at the } \\
\text { boiler outlet [ }{ }^{\circ} \mathrm{C} \text { ] }\end{array}$ & 306 & 294 \\
\hline
\end{tabular}

during 6 weeks. The complete cleaning of equipment that has been periodically performed once per year, were ultimately more effective, and easier. Deposits on the ribs of heater tubes were not sticky and easily removable.

The following figures compare the surface of the incinerator. Figure 2 shows the surface of the combustion apparatus before injection of the reagent, and Figure 3

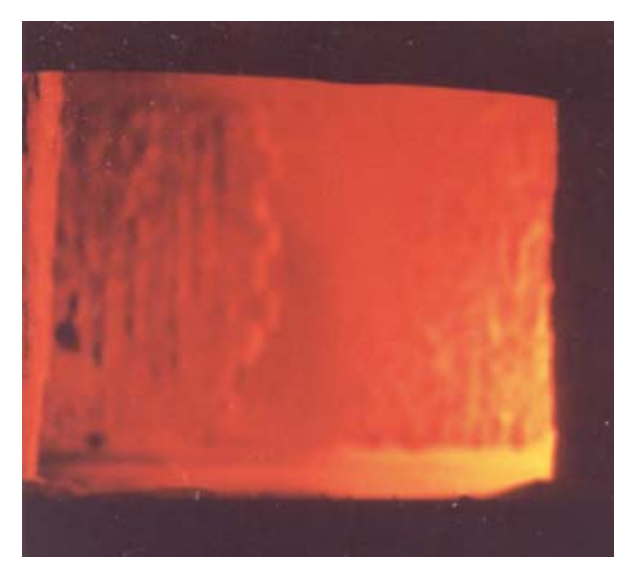

Figure 2. Furnace before injection of reagent

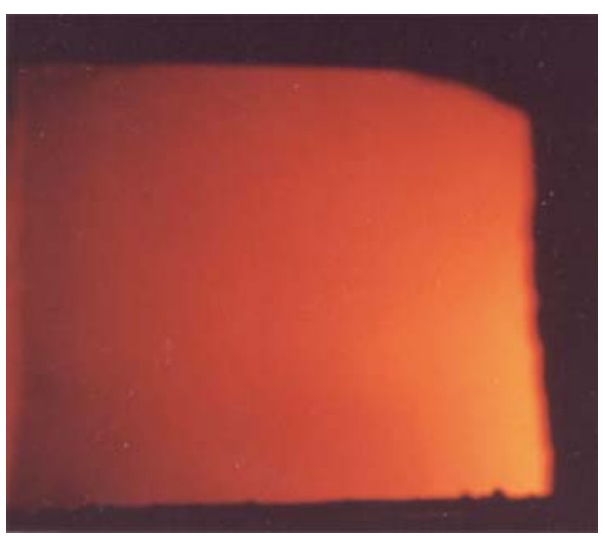

Figure 3. Furnace during injection of reagent shows the area of the combustion device during injection of reagent GEPERSUITTE 2200.

On the basis of visual detection, performed during shutdown after the experiment, it was found the following:

On heat transfer surfaces at the level of the grate deposits fragile and very little sticky have been recorded. In the area of the side membrane walls were found a small amount of deposits in the form of a fine layer of white dust. Above the grid, just below supporting burners the presence of molten ash was recorded.

On the heat transfer surfaces at the bottom of the combustion chamber, there weren't any deposits, only a thin layer of fine white dust.

At the level of the boiler in the primary superheater powder deposition were identified in a thin layer, while in the secondary superheater thin stick coating was recorded. These were the places that were not coated with a layer of reagent.

On the other heat transfer surfaces on the route of the flue gas nonadherent powder deposits were observed only in very small quantities.

Costs of applying this method are minimal. The dose of the reagent is determined depending on the problem and goals to achieve. The average dose of the reagent is only $2-3 \mathrm{~kg}$ per 10 tons of fuel used. There is a very simple application of the reagent by means of nozzles, which does not require any additional work. The advantage is an early return of savings, arising in the connection with the use of the reagent.

\section{CONCLUSION}

In conclusion can be said that continuous use of the technology described above with the film effect was very effective. The aim of the application of the reagent GEPERSUITE 2200 was keeping the combustion chamber longer "pure" and thereby increase its efficiency and reducing interval of steam soot blowers to extend the time between shutdowns of combustion plants, for the reasons of manual cleaning. Finally, it is reducing emissions of pollutants that are released into the atmosphere.

The most careful processing of the project application of the reagent and suitable placement of nozzles together with perfect distribution of the reagent in the combustion chamber are required to achieve the highest efficiency of the process. The main benefits of using the reagent GEPERSUITE 2200 regarding refinery de Sermaize were met. A significant reduction of the total amount needed steam for blowers and reducing the power consumption. Ensuring the highest possible lengthening of the cycle between the cleaning operations of the combustion space and improving the process of heat exchange. Other benefits include also preservation of lifetime and reliability (suppression of expression of high temperature corrosion and fouling of the heating surfaces on the flue gas side in the area of higher flue gas temperatures, increasing the regulation range).

From an economic point of view the use of technology guarantees absolutely certain financial return, if the result is to extend the time between shutdowns of combustion plant, due to clogging by sediment. If we compare the purchasing and operating costs for the use of technology with the benefits that technology brings, 
we get surprisingly positive results. Financial costs arising from shutdowns of combustion plants (thermal power plants, incinerators, etc.) for cleaning purposes of heat transfer surfaces they tend to be very high in addition with loss due to the generated energy and further losses when the device is out of operation.

The advantage of the reagents is their good storability and easy applicability. Used reagents are not toxic and dangerous for the environment and humans; reagents do not contain heavy metals, do not cause corrosion, and do not produce nitrogen oxides. The technology is applicable to all types of combustion installations.

This method has been used for many years successfully in a number of thermal power plants and other combustion plants. The use of the proposed technology is directed to the proposal operationally proven technological process, leading to the optimization of combustion and minimization of implementation cost. High efficiency and safety of this process are confirmed by the users and control authorities.

\section{ACKNOWLEDGEMENTS}

This work was financially by the Ministry of Education, Youth and Sports of the Czech Republic in the „National Feasibility Program I“, project LO1208 „Theoretical Aspects of Energetic Treatment of Waste and Environment Protection against Negative Impacts“.

\section{LITERATURE CITED}

1. Jiang, D., Xu, H., Khan, H.I., Deng, B. \& Zhang, N. (2017). Transport of corrosion products in the steam-water cycle of supercritical power plant. Therm. Engineer. 113, 1164-1169. DOI: 10.1016/j.applthermaleng.2016.11.119.

2. Bilitewski, B., Härdtle, G. \& Marek, K. (1994). Waste Management. Berlin Heidelberg, Germany: Springer-Verlag. ISBN: 3-540-59210-5.

3. Obroučka, K. (2003). Thermal waste treatment and energy recovery. 1st edition. Ostrava: VSB-Technical University of Ostrava. ISBN 80-248-0009-8.

4. Leskens, M., van Kessel, L.B.M. \& Bosgra, O.H. (2005). Model predictive control as a tool for improving the process operation of MSW combustion plants. Waste Managem. 25, 8, 788-798. DOI: 10.1016/j.wasman.2005.03.005.

5. Kuriger, R., Young, D., Mackenzie, M., Sarv, H. \& Trembly, J. (2017). Phase analysis of scale deposition in boiler tubes utilizing steam-assisted gravity drainage produced water. J. Therm. Sci. Engineer. Appl. 9 (1), 011009. DOI: 10.1115/1.4034598.

6. Raman, B., Hall, D.M., Shulder, S.J., Caravaggio, M.F. \& Lvov, S.N. (2016). An experimental study of deposition of suspended magnetite in high temperature-high pressure boiler type environments. Coll.Surf. A: Physicochemical and Engineering Aspects. 508, 48-56. DOI: 10.1016/j.colsurfa.2016.08.018.

7. Gao, Z., Zhao, H., Fan, J., Yin, L. \& Liao, Y. (2016). Study on structure optimization and heat-transfer characteristics of high-tennperature convective heating surface in pressurized oxy-fuel boilers. J. Chinese Soc. Power Engineer. 36(10), 773-780. ISSN: 16747607.

8. Li, J., Zhai, Z., Wang, J. \& Huang, S. (2016). On-line fouling monitoring model of condenser in coal-fired power plants. Therm. Engineer. 104, 628-635. DOI: 10.1016/j.applthermaleng.2016.04.131.

9. Jalalirad, M.R., Abd-Elhady, M.S. \& Malayeri, M.R. (2013). Cleaning action of spherical projectiles in tubular heat exchangersInternational. J. Heat Mass Trans. 57, (2), 491-499. DOI: 10.1016/j.ijheatmasstransfer.2012.10.071.
10. Garba, M.U., Ingham, D.B., Ma, L., Degereji, M.U., Pourkashanian, M. \& Wiliams, A. (2013). Modelling of deposit formation and sintering for the co-combustion of coal with biomass. Fuel 113(11), 863-872. DOI: 10.1016/j.fuel.2012.12.065. 11. Decree of the Czech Ministry of the Environment No $415 / 2012$ Coll., on permissible level of pollution and the discovery and implementation of certain other provisions of the Clean Air Act (emission regulation).

12. Li, J., Wang, P. \& Cheng, L. (2016). Characteristics of ash deposition on a novel heat transfer surface. Huag. Xue./CIESC J. 67(9), 3598-3606. DOI: 10.11949/j.issn.0438-1157.20160232. 13. Iannacone, M.M., Castle, J.W. \& Rodgers, Jr., J.H. (2009). Characterization of flue gas desulfurization particulates in equalization basins. Fuel 88(9), 1580-1587. DOI: 10.1016/j. fuel.2009.02.035

14. Bigham, J.M., Kost, D.A., Stehouwer, R.C., Beeghly, J.H., Fowler, R., Traina, S.J., Wolfe, W.E. \& Dick, W.A. (2005). Mineralogical and engineering characteristics of dry flue gas desulfurization products. Fuel 84(14-15), 1839-1848. DOI: 10.1016/j.fuel.2005.03.018.

15. Zacco, A., Borgese, L., Gianoncelli, A., Depero, L.E. \& Bontempi, E. (2014). Review of fly ash inertisation treatments and recycling. Environ. Chem. Lett. 12(1), 153-175. DOI: 10.1007/s10311-014-0454-6.

16. Fry, A., Adams, B., Davis, K., Swensen, D. \& Cox, W. (2012). Fire-side corrosion of heat transfer surface materials with air- and oxy-coal combustion. In Air and Waste Management Association - Power Plant Air Pollutant Control "MEGA" Symposium 2012, Baltimore, MD, USA; 20-23 $3^{\text {rd }}$ August 2012. 17. Alba, N., Gassó, S., Lacorte, T. \& Baldasano, J.M. (1997). Characterization of Municipal Solid Waste incineration residues from facilities with different air pollution control systems. $J$. Air Waste Managem. Assoc. 47(11), 1170-1179. ISSN: 10962247. 18. Van Kessel, L.B.M., Leskens, M. \& Brem, G. (2002). Calorific value sensor and validation of dynamic models applied to municipal solid waste combustion. IChemE The Chemical Engineer. 80 B5, 245-255. DOI: 10.1205/095758202762277605. 19. Breeding, Ch., Tandra, D. \& Shah, S. (2010). Boiler Cleaning Using ISB (Intelligent Soot Blowing) System Integration. In ASME 2010 Power Conference, Chicago, USA, 13-15 $5^{\text {th }}$ July 2010. 20. A.I.T. Drivex. (2003). Contre l'encrassement des chaudieres, Revue du Papier Carton, Issue 65, October 2003 (pp. 46-48). 21. A.I.T. DRIVEX. Available on the website: <http://www. drivex.fr/Catalogue.htm> 